\title{
Recent advancements in supermicrosurgical treatment of lymphedema
}

\author{
Samer Jabbour ${ }^{1}$, Edward I. Chang ${ }^{2}$ \\ 'Department of Plastic Surgery, Medstar Healthcare System, Georgetown, Washington D.C. 20007, USA. \\ ${ }^{2}$ Department of Plastic Surgery, University of Texas, MD Anderson Cancer Center, Houston, TX 77030, USA.
}

Correspondence to: Dr. Edward I. Chang, Department of Plastic Surgery, Unit 443, University of Texas, MD Anderson Cancer Center, 1515 Holcombe Boulevard, Houston, TX 77030, USA. E-mail: eichang@mdanderson.org

How to cite this article: Jabbour S, Chang El. Recent advancements in supermicrosurgical treatment of lymphedema. Plast Aesthet Res 2021;8:43. https://dx.doi.org/10.20517/2347-9264.2021.59

Received: 7 Jun 2021 First Decision: 5 Jul 2021 Revised: 12 Jul 2021 Accepted: 28 Jul 2021 First online: 9 Aug 2021

Academic Editor: Matthew L. Iorio Copy Editor: Xi-Jun Chen Production Editor: Xi-Jun Chen

\begin{abstract}
Surgical treatment for lymphedema has undergone tremendous advancements over the years, with the earliest techniques focusing on ablative procedures such as liposuction and direct excision. With modern advancements in technology, equipment, imaging, and microscope optics, physiologic procedures have emerged as the standard of care for lymphedema at high-volume institutions and centers of excellence. The lymphovenous bypass and the vascularized lymph node transfer operations have both proven to be effective means for treatment and improving the quality of life of patients suffering from lymphedema. However, with the established foundation of knowledge and experience, innovative approaches to optimize outcomes in patients undergoing supermicrosurgical treatment are constantly evolving. The present review presents a historical review of the lymphovenous bypass and vascularized lymph node transfer procedures and introduces some novel expansions of both techniques in the field of lymphedema surgery.
\end{abstract}

Keywords: Lymph-venous bypass, vascularized lymph node transfer, prophylactic repair of vessels in the axilla with immediate LVB

\section{INTRODUCTION}

Lymphedema is a chronic, debilitating condition that results most commonly from treatment for cancer in 
the United States and most industrialized nations across the world. The combination of surgical resection, including regional nodal dissections, chemotherapy, and radiation therapy, places patients at significant risks for developing lymphedema due to compromised drainage of lymphatic fluid from the limb ${ }^{[1-4]}$. As the obstruction progresses, the lymphatic fluid leaks into the surrounding subcutaneous tissue leading to a vicious cycle of inflammation that further compromises the drainage from the limb resulting in fat deposition and fibrosis. Historically, treatment focused on ablative procedures to reduce and remove the fat and fluid from the arm or leg via direct excision or liposuction. However, modern techniques for the treatment of lymphedema focus on physiological approaches aimed to restore the drainage of lymphatic fluid from the affected limb $b^{[-8]}$.

One option is the lymphovenous bypass (LVB), where an anastomosis is completed between a lymphatic vessel and a recipient venule ${ }^{[9,10]}$. Given the small size of the vessels, the concept of super microsurgery was coined, designating the surgical repair of these vessels that are less than one millimeter in size [Figure 1]. With the advancements in the design of specialized instruments, microscopic sutures, improved optics in operative microscopes, different imaging modalities, and experience, this approach has proven to be an effective and reproducible method to allow the lymphatic fluid to drain into the systemic circulation, thereby restoring the egress of fluid from the extremity. As the fluid drains into the bloodstream, the swelling improves, and the overwhelming majority of patients find an improvement in the heaviness of their arm or leg, decreased dependency on compression garments and need for conservative therapies, and reduced risks and frequency of infection and cellulitis. Early studies demonstrated efficacy only with earlystage lymphedema, but more recent studies suggest that the technique can also be extremely effective even in late-stage and more advanced lymphedema ${ }^{[1,12]}$.

The second option that has also grown in popularity in recent times is the vascularized lymph node transfer (VLNT). Studies have demonstrated improvements in patients who have undergone this operation where lymph nodes are taken from one location and transferred to the affected extremity. The precise mechanism of action remains unknown, but the two predominant theories are either via a pump mechanism or through lymphangiogenesis ${ }^{[13-15]}$. A number of different donor sites have been described, the most popular of which include the supraclavicular nodes, the submental nodes, the lateral thoracic nodes, the inguinal nodes, and intra-abdominal nodes, including the gastroepiploic nodes or the omentum and the mesenteric nodes ${ }^{[16]}$. Most super microsurgeons specializing in VLNT have a preferred donor site and have reported consistent outcomes confirming the efficacy of lymph node transfers; however, regardless of which donor site is selected, the effectiveness seems to be equivalent except for the lateral thoracic nodes, which have higher complication rates compared to the other donor sites ${ }^{[17]}$. Overall, the outcomes using the lymph node transfer approach have proven to be promising, and more and more data has continued to confirm its efficacy.

\section{Lymphovenous bypass}

The lymphovenous bypass procedure has been popularized by Koshima et al. ${ }^{[18]}$ and led to a resurgence of this technique for the treatment of lymphedema in a variety of different areas, but most commonly in the arms and legs. The technique is based on the localization of the remaining lymphatic vessels in the affected area that can be rerouted, creating a shunt from the obstructed lymphatic system into the systemic circulation. The vessels are typically less than one millimeter in size, which has led to the term super microsurgery, and with the modern technology available, the anastomosis can be readily completed by trained microsurgeons. Occasionally, the vessels can be larger, allowing the anastomosis to be completed using a venous coupling device (Synovis, Inc., Alabama) ${ }^{[19]}$. Whether a coupled LVB or a hand-sewn LVB is superior remains to be determined, but perhaps the use of the coupler may improve the long-term patency of the LVB, preventing compression and thrombosis of the bypass [Figure 2]. 


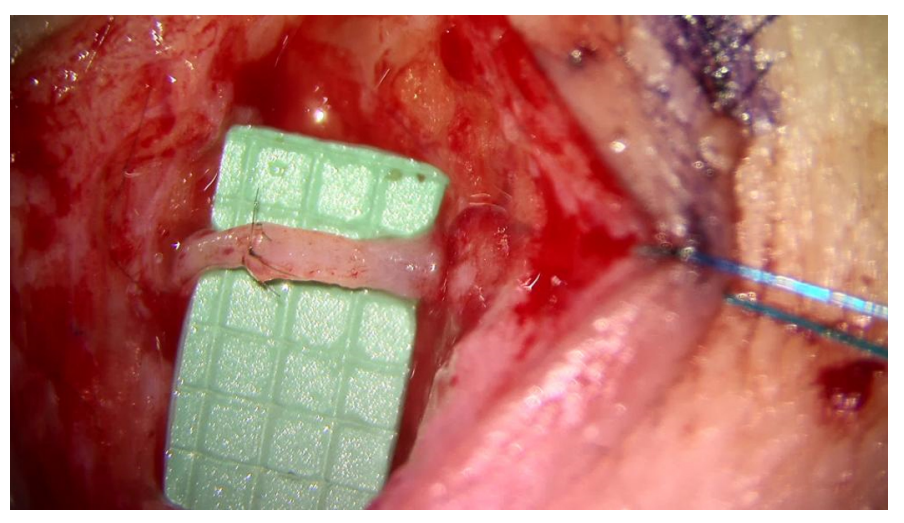

Figure 1. Lymphovenous bypass performed, allowing the lymphatic fluid to drain into the recipient vein. The green background has markings delineating $1 \mathrm{~mm} \times 1 \mathrm{~mm}$ squares demonstrating the submillimeter vessels that are repaired.

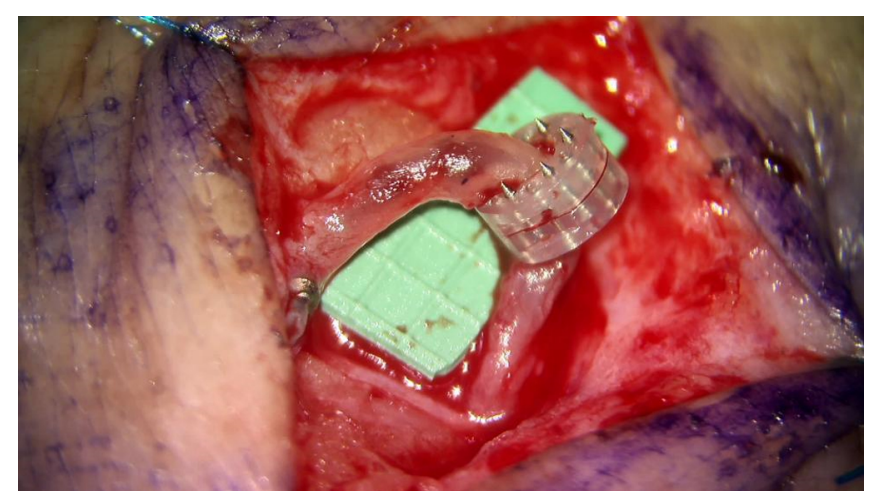

Figure 2. Lymphovenous anastomosis performed with a venous coupling device completing the anastomosis without the use of sutures.

\section{Imaging modalities}

Since the re-emergence of the bypass technique, the primary modality for identifying the lymphatic vessels centered on the use of indocyanine green (ICG) lymphangiography ${ }^{[20-22]}$. The use of ICG has been welldescribed for tissue perfusion; however, the field of lymphedema surgery utilizes the property that ICG is also absorbed into the lymphatic system when injected into the subcutaneous space rather than intravascularly. Using different infrared cameras available on the market, one can map the lymphatic anatomy of the affected limb or body part [Figure 3]. However, the ability to perform an LVB is also dependent on the identification of a recipient vein of suitable size. New imaging technology is now available to help identify veins in a non-invasive fashion, increasing the efficiency of the operation and planning of the incisions for the bypass [Figure 4]. The use of magnetic resonance lymphangiography has demonstrated some promising outcomes in identifying potential targets for the bypass operation; however, consideration of costs and the impact on patients requiring an additional exam and time off of work need to be factored into the true benefit of the MR in comparison to other modalities ${ }^{[22,23]}$.

However, one of the greatest innovations that have tremendous potential in revolutionizing the LVB procedure is the use of ultra-high frequency ultrasound ${ }^{[24,25]}$. This innovative technology allows visualization of the lymphatic vessels and the veins, and the resolution permits the trained and experienced microsurgeon to be able to distinguish between the two different types of vessels. This allows one to effectively and easily identify the lymphatic channel and recipient vein without an ICG injection and can detect vessels that were not previously visualized because of the limitations in the depth of penetration of the infrared camera. 


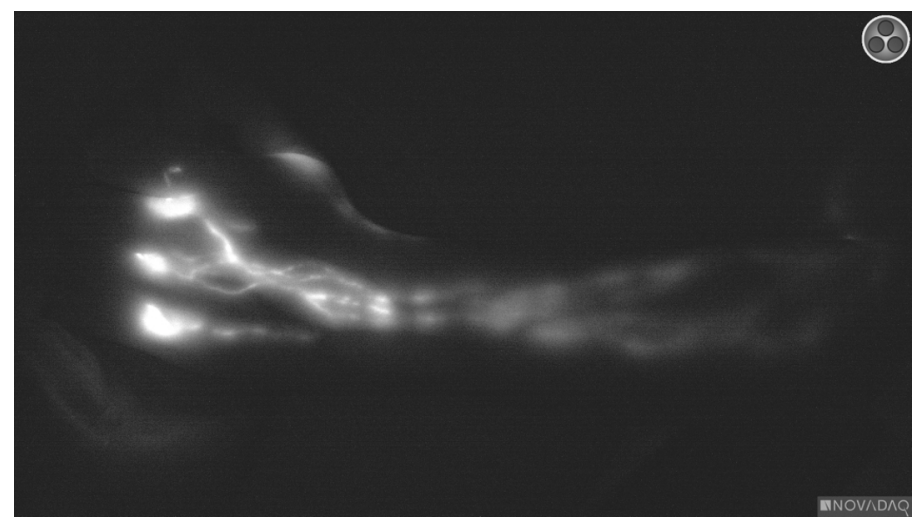

Figure 3. Indocyanine green (ICG) lymphatic mapping demonstrating the linear lymphatic channels that have absorbed the ICG fluorescent dye. This is a linear pattern or an MD Anderson stage 1 without obvious dermal backflow.

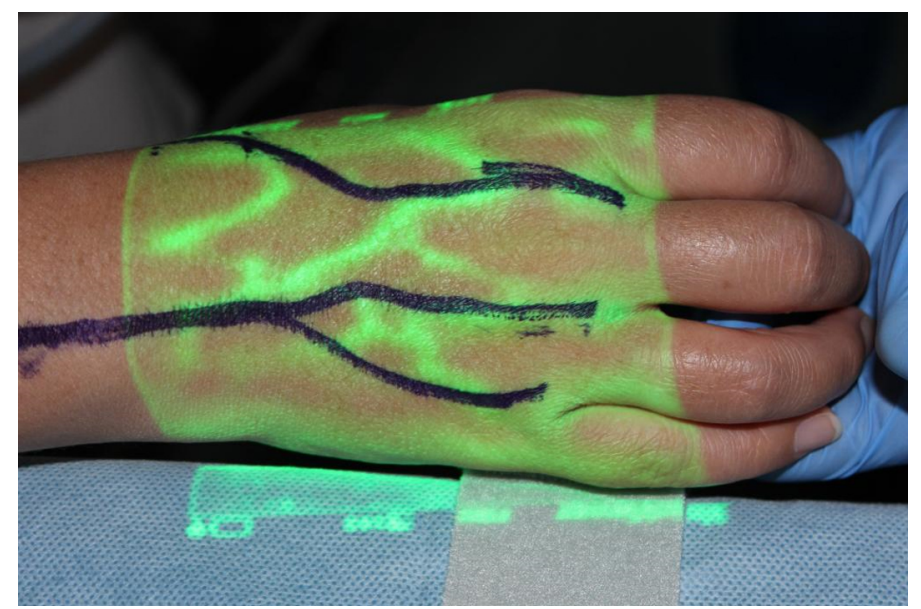

Figure 4. Vein finder device utilized to identify potential targets for recipient veins.

While the technology is still in its infancy, early utilization of the ultra-high frequency ultrasound can potentially be a game changer for the field of lymphedema surgery.

\section{Prophylactic lymphovenous bypass}

With the documented improvements in patients who have undergone an LVB to treat their lymphedema, the concept is now growing in popularity for the prevention of lymphedema, particularly in patients undergoing treatment for breast cancer. In patients who are undergoing axillary dissection, using the lymphatic preventative healing approach (LYMPHA), the lymphatic vessels draining the arm are repaired to a recipient vein in the axilla to preserve the drainage of the arm in hopes of preventing patients from developing lymphedema ${ }^{[26-28]}$. Early reports of this technique have demonstrated promising results with a significant reduction in the incidence and risks of lymphedema in most studies. However, the actual technique varies from study to study and from one surgeon to another, and longer follow-up is needed to evaluate the true benefit of this approach in reducing the incidence of lymphedema in high-risk patients.

It is the authors' preference to employ axillary reverse mapping when performing the prophylactic repair of vessels in the axilla with immediate LVB (PREVAIL) ${ }^{[29]}$. This allows direct visualization and identification of the lymphatic vessels that are draining the upper extremity and requires close collaboration with the breast 
surgical oncologists who are able to preserve the vessels for the immediate LVB [Figure 5]. All LVB are performed using the standard LVB technique, where an end-to-end anastomosis is performed between the lymphatic and recipient vein. In certain circumstances, when the axillary dissection is more extensive due to advanced disease, there are a limited number of suitable recipient veins. Rather than gathering the lymphatic channels into a single vein using intussusception, the authors still favor a true anastomosis to ensure patency of the anastomoses using the PREVAIL technique. We do not recommend sacrificing the main or both venae comitantes (VC) of the thoracodorsal vessels as this would preclude the use of a pedicle latissimus dorsi flap in the future. However, one VC can be sacrificed, or a branch such as the serratus branch is often available and can serve as a recipient vein. In other circumstances, when only a single larger vein is available, a double-barrel approach can be performed, performing a true anastomosis of two lymphatic vessels into a single vein, again avoiding intussuscepting the lymphatic vessel into the vein [Figure 6].

While most studies again have demonstrated success in reducing the risks of lymphedema, longer follow-up studies are needed to confirm the true efficacy. Further, other studies have also claimed to have significant reductions in the risk of lymphedema without using super microsurgical techniques. However, most studies are limited to one year or a year and a half, with only one study that followed patients up to 4 years ${ }^{[30]}$. Nonetheless, it is the author's opinion that lymphedema cannot be cured once a patient truly has developed lymphedema, and therefore, prevention is the key to managing the risk of lymphedema in high-risk patients and preserving patients' quality of life.

\section{Vascularized lymph node transfer}

The second primary technique for surgical treatment of lymphedema is a VLNT. While there is a paucity of literature comparing one donor site to another, most studies have demonstrated significant benefits and improvement with each respective donor site ${ }^{[31-35]}$. A number of different donor sites have been described, and the decision for which donor site to utilize is based on the availability of donor sites and patients' acceptance of risks and complications. While the submental donor site has no risk of donor site lymphedema, patients are cautioned regarding the prevalence of the scar and the potential risk of injury to the marginal mandibular nerve. There are rare reports of donor site lymphedema following the harvest of the supraclavicular nodes, but again the scar may be apparent and should be discussed ${ }^{[36,37]}$. We also favor the right side to avoid injury to the thoracic duct, which can result in a difficult complication if it is injured on the left side. The inguinal donor site has a well-concealed scar and is a donor site that can provide additional volume, which is often needed following a complete scar release. However, precautions are necessary to avoid the risk of precipitating lymphedema in the lower extremity following harvest. The intraabdominal options are very appealing due to a well-concealed scar and no reported risks of donor site lymphedema; however, patients should understand the risks of entering the abdomen ${ }^{[38]}$. The mesenteric nodes and the omentum/gastroepiploic nodes are both increasing in popularity [Figure 7]. Injury to adjacent structures, adhesions, and risks of bowel obstruction and an incisional hernia should all be thoroughly discussed with patients. Harvest of the omentum or the gastroepiploic lymph nodes has also been associated with pancreatitis, while harvest of the mesenteric nodes can also lead to ischemic bowel, necessitating a bowel resection ${ }^{[39,40]}$.

\section{Combined breast reconstruction and vascularized lymph node transfer}

For patients suffering from upper extremity lymphedema secondary to breast cancer treatment who are also interested in breast reconstruction, the combined approach is the authors' recommended approach as the patient can obtain an aesthetic autologous breast reconstruction in combination with a lymph node transfer in a single operation with minimal risks ${ }^{[41-43]}$ [Figure 8]. For all patients undergoing a combined deep inferior epigastric perforator (DIEP) and VLNT, preoperative lymphoscintigraphy and reverse mapping are 


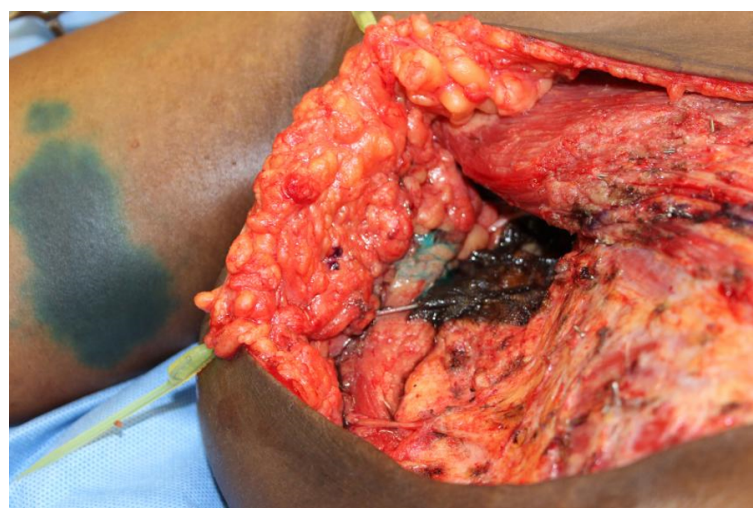

Figure 5. Axillary reverse mapping using isosulfan blue to identify the lymphatic vessels. The use of the chromophore dye allows visualization of the lymphatic channels during the axillary dissection, which facilitates the prophylactic repair of vessels in the axilla with immediate lymphovenous bypass (PREVAIL).

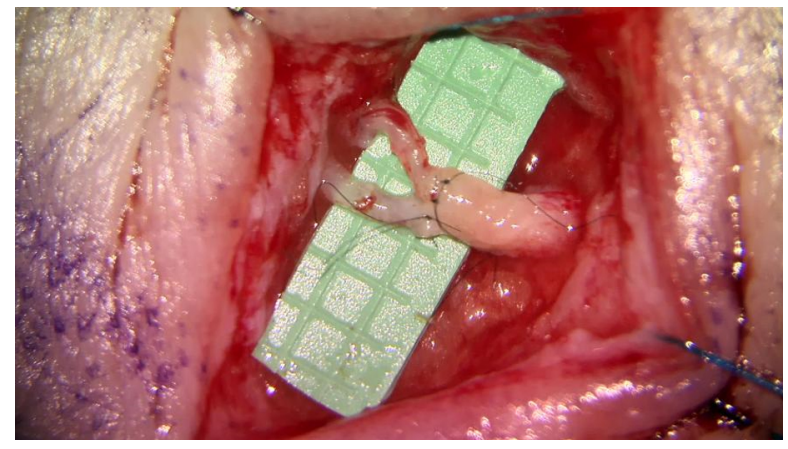

Figure 6. Lymphovenous bypass performed using a double-barrel approach with the anastomosis of two lymphatic vessels into a single larger caliber recipient vein.

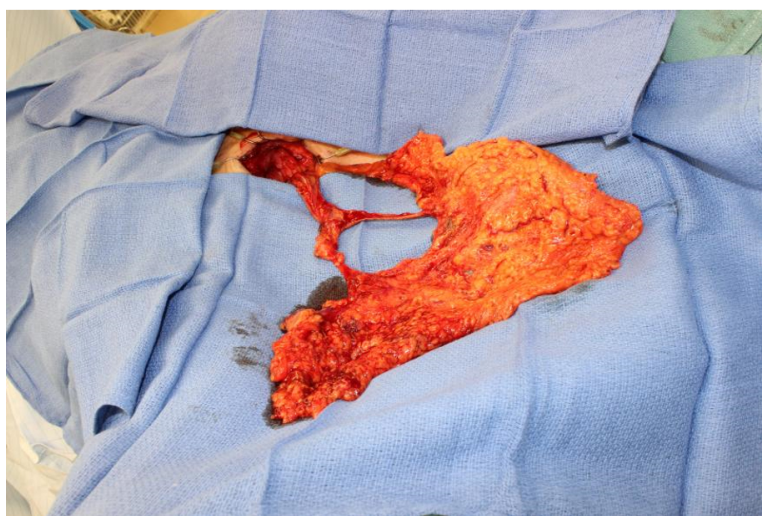

Figure 7. Free omental gastroepiploic lymph node transfer to the axilla for treatment of lymphedema.

critical to minimize the risks of donor site lymphedema ${ }^{[43,44]}$. At the authors' institution, we routinely obtain SPECT-CT and lymphoscintigraphy for preoperative planning during VLNT when donor sites can potentially place the patient at risk for donor site lymphedema. This is critical in patients undergoing an inguinal node transfer or if the VLNT is combined with a DIEP flap breast reconstruction. The decision to perform an additional arterial, venous, or dual microvascular anastomosis remains an area of debate and controversy. It is the author's preference to employ ICG angiography to evaluate the perfusion of the lymph 


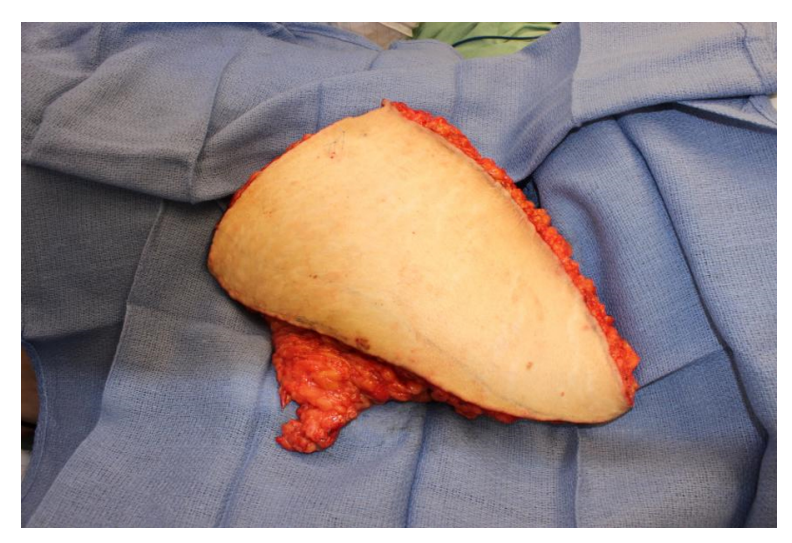

Figure 8. Free deep inferior epigastric artery perforator flap combined with a pedicle inguinal lymph node transfer for simultaneous breast reconstruction and treatment of breast cancer-related lymphedema.

nodes to determine whether additional anastomoses are needed. Injection of ICG intravascularly is utilized to confirm adequate perfusion of the nodes and sufficient clearance of the dye, as is commonly used to assess perfusion and congestion of any other free flap. If the ICG angiography demonstrates compromised perfusion or congestion of the nodes, then an additional arterial or venous anastomosis is performed, respectively. The availability of recipient vessels should also be considered as we tend to preserve the main thoracodorsal vessels in the setting that the DIEP flap is lost; the latissimus dorsi flap remains a suitable option for breast reconstruction.

While the combined DIEP and VLNT approach has demonstrated promising outcomes, the authors hypothesized whether using both LVB with VLNT would have a synergistic effect and can achieve superior outcomes to either one alone. The recent combined LVB and VLNT approach has now become the standard approach at the authors' institution. The combined breast reconstruction, including LVB and inguinal to axillary node transfer (BRILIANT) approach, employs both the supermicrosurgical techniques to maximize the improvement in patients who have breast cancer-related lymphedema (BCRL ${ }^{[45]}$. A prospective study has demonstrated superior outcomes using both LVB and VLNT compared to VLNT alone when combined with DIEP flap breast reconstruction ${ }^{[45,46]}$.

\section{Combined LVB and VLNT}

Given the improvements noted in patients who underwent the BRILIANT approach for breast reconstruction and BCRL, the same concept has been applied to all patients who present for surgical treatment of lymphedema. We and others have demonstrated that the combined LVB and VLNT techniques seem to have superior outcomes to either one alone, which has now become the standard approach at our institution ${ }^{[47]}$. While there is an ongoing debate regarding distal $v s$. proximal placement of the nodes for VLNT, anatomical placement is the authors' recommendation, as there are also benefits to a thorough scar release in patients who have undergone a formal axillary or inguinal dissection ${ }^{[48]}$. So for patients who have undergone an axillary dissection or an inguinal node dissection, we prefer to place the lymph nodes into the location of the nodal dissection. Whether placing the VLNT proximally into the anatomic location or distally to allow gravity to aid in generating a favorable hydrostatic pressure gradient remains an area of considerable debate. For patients who have undergone a pelvic node dissection for gynecological or urological malignancies, the VLNT is placed in the most problematic area of the lower extremity. Placing the VLNT in the proximal, anatomic region and combining the LVB in the distal extremity provides a synergistic improvement in the entire affected limb. Patients often notice an immediate improvement in the limb from the LVB, but with time, patients begin to notice a further improvement as 
the transferred lymph nodes begin to function. Others who have employed the combined approach have also demonstrated similar benefits with this strategy for the treatment of lymphedema ${ }^{[4,50]}$.

\section{Lymphatic vessel transfer}

Another technique that was previously described as a transfer of a soft tissue flap that included lymphatic vessels is beginning to witness a resurgence of this approach. The lymphatic interpositional flap transfer functions based on transferring and orienting a soft tissue flap that allows for the existing lymphatic channels in the affected limb to inosculate with the lymphatic vessel transfer allowing the fluid drainage and absorption from the extremity. Early reports of this approach were performed as a means of preventing lymphedema by restoring lymphatic flow from the injured $\operatorname{leg}^{[51,52]}$. However, the concept has now grown as a therapeutic strategy to treat patients with lymphedema, and we await reports of early outcomes to evaluate its true efficacy.

\section{DISCUSSION}

The field of lymphedema surgery has undergone tremendous advancements in a remarkably short period of time since its resurrection in the modern age of super microsurgery with the introduction of ICG imaging, specially designed instruments, and advanced microscopes with superior magnification and optics. With the growing number of surgeons interested in lymphedema surgery, it is becoming a critical component of microsurgery fellowship programs to provide broad and in-depth exposure to the techniques that will allow the future of the field to continue to grow and evolve. After providing budding microsurgeons with the techniques and premises in lymphedema, innovative ideas expanding on or perhaps even challenging the established concepts are sure to arise. Since the earliest reports of lymphedema surgery at our institution, the foundation was established to innovate new approaches to treat lymphedema ${ }^{[53]}$. The description of the laparoscopic omental harvest defined the basis for one of the most popular vascularized lymph node donor sites currently employed at many institutions ${ }^{[40]}$. The expansion of the BRILIANT approach stems from the work of pioneers in the field ${ }^{[54,55]}$. While many lymphedema surgeons have their preferred donor site, there is no single optimal donor site, and the decision for selecting one versus another is based on patient risk profiles and availability of donor sites and surgeon experience and preference. We offer patients the entire spectrum of VLNT donor sites and present a transparent description of the advantages and potential complications and risks associated with each site so the patient can make the best decision ${ }^{[16]}$.

As techniques, technology, and experience continue to grow and evolve, the limits of lymphedema surgery have not yet been defined. Novel approaches to treat more extensive lymphedema continue to emerge, and more and more patients have now been considered candidates for lymphedema surgery compared to previously ${ }^{[2,56]}$. Despite these advancements, some patients are still relegated to debulking procedures which are still a critical component in the algorithm to surgical treatment of lymphedema ${ }^{[77,58]}$. Given that lymphedema has both a fluid component as well as a fat component, often debulking operations are necessary to achieve the most optimal result. In the hands of some skilled surgeons, long-term efficacy and improvement with lymphedema have been achieved with debulking procedures alone ${ }^{[5-61]}$. Therefore, the authors tend to supplement the physiologic procedures with a debulking operation, typically 6-12 months following the LVB and VLNT.

While many of these strategies are designed to improve patient symptoms and quality of life suffering from lymphedema, there is no cure for lymphedema, in our opinion. While volumetric measurements may normalize and the need for complete decongestive therapy eliminated, the drainage of the limb is not fully restored, and any injury or infection can lead to recurrence. However, there are novel concepts that are striving to achieve a cure. One future treatment strategy aims to use the concept of a free flap as a vector for 
gene therapy to enhance tissue regeneration ${ }^{[2,63]}$. Combining stem cell therapy with increased expression of VEGF-C in a VLNT with gene therapy to augment and enhance the process of lymphangiogenesis hopes to achieve more dramatic and improved outcomes. Preliminary outcomes have demonstrated promising results, and future studies are developing, which may ultimately revolutionize the treatment and perhaps even cure lymphedema ${ }^{[64-66]}$. Other alternative strategies are also emerging on a regular basis using collagen scaffolds to direct lymphangiogenesis which is based on prior studies using muscle as a biologic bridge ${ }^{[67,68]}$. Perhaps there are potential medical strategies that will revolutionize the treatment of lymphedema, making the need for surgery obsolete ${ }^{[69,70]}$.

Ultimately, the future of lymphedema surgery lies in prevention. As the need for full regional nodal dissections decreases and preventative strategies become more and more popular, hopefully, the incidence of lymphedema can be reduced significantly. Preliminary early outcomes in the prophylactic repair of the lymphatic vessels during an axillary dissection are promising. However, a number of different techniques are currently employed, and longer follow-up is needed to ascertain the true efficacy of the PREVAIL and LYMPHA technique ${ }^{[7,72]}$. However, despite the reduction in the risk of developing lymphedema, as treatment modalities continue to improve survival, there will undoubtedly still be a need for the treatment of lymphedema. Regardless, the goals and objectives aim to improve the quality of life of patients suffering from this debilitating condition; however, there remains a need for a comprehensive, validated patientreported outcomes (PROs) metric ${ }^{[73,74]}$. Many of the current PROs measures are quite functional and provide important objective measures for patients documenting the benefits of lymphedema surgery for this complex cohort of patients. While plastic surgeons, particularly those with experience with microsurgery, are well-acquainted with the benefits of lymphedema surgery, we must continue to advance the field and optimize the treatment for those suffering from lymphedema.

\section{CONCLUSIONS}

The field of lymphedema surgery continues to grow, expand, and evolve, which is critical to optimizing patient outcomes and improve patients' quality of life. The field has already grown tremendously since its inception, but the foundation has been prepared for further advancements in the near future.

\section{DECLARATIONS}

\section{Authors' contributions}

Were both responsible for composing the manuscript, performing the literature review and critical editing of the manuscript: Chang EI, Jabbour S

\section{Availability of data and materials}

Not applicable.

\section{Financial support and sponsorship}

None.

\section{Conflicts of interest}

Both authors declared that there are no conflicts of interest.

\section{Ethical approval and consent to participate}

Not applicable. 


\section{Consent for publication}

Not applicable.

\section{Copyright}

(c) The Author(s) 2021.

\section{REFERENCES}

1. Naoum GE, Roberts S, Brunelle CL, et al. Quantifying the impact of axillary surgery and nodal irradiation on breast cancer-related lymphedema and local tumor control: long-term results from a prospective screening trial. J Clin Oncol 2020;38:3430-8. DOI PubMed PMC

2. Armer JM, Ballman KV, McCall L, et al. Factors associated with lymphedema in women with node-positive breast cancer treated with neoadjuvant chemotherapy and axillary dissection. JAMA Surg 2019;154:800-9. DOI PubMed PMC

3. Byun HK, Chang JS, Im SH, et al. Risk of lymphedema following contemporary treatment for breast cancer: an analysis of 7617 consecutive patients from a multidisciplinary perspective. Ann Surg 2021;274:170-8. DOI PubMed

4. McLaughlin SA, Wright MJ, Morris KT, et al. Prevalence of lymphedema in women with breast cancer 5 years after sentinel lymph node biopsy or axillary dissection: objective measurements. J Clin Oncol 2008;26:5213-9. DOI PubMed PMC

5. Silva AK, Chang DW. Vascularized lymph node transfer and lymphovenous bypass: novel treatment strategies for symptomatic lymphedema. J Surg Oncol 2016;113:932-9. DOI PubMed

6. Raju A, Chang DW. Vascularized lymph node transfer for treatment of lymphedema: a comprehensive literature review. Ann Surg 2015;261:1013-23. DOI PubMed

7. Chang EI, Skoracki RJ, Chang DW. Lymphovenous anastomosis bypass surgery. Semin Plast Surg 2018;32:22-7. DOI PubMed PMC

8. Garza RM, Chang DW. Lymphovenous bypass for the treatment of lymphedema. J Surg Oncol 2018;118:743-9. DOI PubMed

9. Chang DW, Suami H, Skoracki R. A prospective analysis of 100 consecutive lymphovenous bypass cases for treatment of extremity lymphedema. Plast Reconstr Surg 2013;132:1305-14. DOI PubMed

10. Scaglioni MF, Fontein DBY, Arvanitakis M, Giovanoli P. Systematic review of lymphovenous anastomosis (LVA) for the treatment of lymphedema. Microsurgery 2017;37:947-53. DOI PubMed

11. Yang JC, Yen YH, Wu SC, Lin WC, Chiang MH, Hsieh CH. Supermicrosurgical lymphaticovenous anastomosis as an alternative treatment option for patients with lymphorrhea. Plast Reconstr Surg 2019;144:1214-24. DOI PubMed

12. Yang JC, Wu SC, Lin WC, Chiang MH, Chiang PL, Hsieh CH. Supermicrosurgical lymphaticovenous anastomosis as alternative treatment option for moderate-to-severe lower limb lymphedema. J Am Coll Surg 2020;230:216-27. DOI PubMed

13. Garcés M, Pons G, Mirapeix R, Masià J. Intratissue lymphovenous communications in the mechanism of action of vascularized lymph node transfer. J Surg Oncol 2017;115:27-31. DOI PubMed

14. Liu HL, Pang SY, Lee CC, Wong MM, Chung HP, Chan YW. Orthotopic transfer of vascularized groin lymph node flap in the treatment of breast cancer-related lymphedema: Clinical results, lymphoscintigraphy findings, and proposed mechanism. $J$ Plast Reconstr Aesthet Surg 2018;71:1033-40. DOI PubMed

15. Joseph WJ, Aschen S, Ghanta S, et al. Sterile inflammation after lymph node transfer improves lymphatic function and regeneration. Plast Reconstr Surg 2014;134:60-8. DOI PubMed PMC

16. Chang EI, Chu CK, Hanson SE, Selber JC, Hanasono MM, Schaverien MV. Comprehensive overview of available donor sites for vascularized lymph node transfer. Plast Reconstr Surg Glob Open 2020;8:e2675. DOI PubMed PMC

17. Scaglioni MF, Arvanitakis M, Chen YC, Giovanoli P, Chia-Shen Yang J, Chang EI. Comprehensive review of vascularized lymph node transfers for lymphedema: Outcomes and complications. Microsurgery 2018;38:222-9. DOI PubMed

18. Koshima I, Inagawa K, Urushibara K, Moriguchi T. Supermicrosurgical lymphaticovenular anastomosis for the treatment of lymphedema in the upper extremities. J Reconstr Microsurg 2000;16:437-42. DOI PubMed

19. Sisk GC, Shuck JW, Lopez M, Chang EI. Lymphovenous anastomosis using the venous coupler. J Plast Reconstr Aesthet Surg 2020;73:983-1007. DOI PubMed

20. Chang EI, Chu CK, Chang EI. Advancements in imaging technology for microvascular free tissue transfer. J Surg Oncol 2018;118:729-35. DOI PubMed

21. Yamamoto T, Yamamoto N, Doi K, et al. Indocyanine green-enhanced lymphography for upper extremity lymphedema: a novel severity staging system using dermal backflow patterns. Plast Reconstr Surg 2011;128:941-7. DOI PubMed

22. Pons G, Clavero JA, Alomar X, Rodríguez-Bauza E, Tom LK, Masia J. Preoperative planning of lymphaticovenous anastomosis: the use of magnetic resonance lymphangiography as a complement to indocyanine green lymphography. J Plast Reconstr Aesthet Surg 2019;72:884-91. DOI PubMed

23. Zeltzer AA, Brussaard C, Koning M, et al. MR lymphography in patients with upper limb lymphedema: The GPS for feasibility and surgical planning for lympho-venous bypass. J Surg Oncol 2018;118:407-15. DOI PubMed

24. Bianchi A, Visconti G, Hayashi A, Santoro A, Longo V, Salgarello M. Ultra-high frequency ultrasound imaging of lymphatic channels correlates with their histological features: A step forward in lymphatic surgery. J Plast Reconstr Aesthet Surg 2020;73:1622-9. DOI PubMed

25. Cha HG, Oh TM, Cho MJ, et al. Changing the paradigm: lymphovenous anastomosis in advanced stage lower extremity lymphedema. 
Plast Reconstr Surg 2021;147:199-207. DOI PubMed

26. Johnson AR, Fleishman A, Granoff MD, et al. Evaluating the impact of immediate lymphatic reconstruction for the surgical prevention of lymphedema. Plast Reconstr Surg 2021;147:373e-81e. DOI PubMed

27. Cook JA, Sasor SE, Loewenstein SN, et al. Immediate lymphatic reconstruction after axillary lymphadenectomy: a single-institution early experience. Ann Surg Oncol 2021;28:1381-7. DOI PubMed

28. Squitieri L, Rasmussen PW, Patel KM. An economic analysis of prophylactic lymphovenous anastomosis among breast cancer patients receiving mastectomy with axillary lymph node dissection. J Surg Oncol 2020;121:1175-8. DOI PubMed

29. Schwarz GS, Grobmyer SR, Djohan RS, et al. Axillary reverse mapping and lymphaticovenous bypass: lymphedema prevention through enhanced lymphatic visualization and restoration of flow. J Surg Oncol 2019;120:160-7. DOI PubMed

30. Boccardo F, Casabona F, De Cian F, et al. Lymphatic microsurgical preventing healing approach (LYMPHA) for primary surgical prevention of breast cancer-related lymphedema: over 4 years follow-up. Microsurgery 2014;34:421-4. DOI PubMed

31. Coriddi M, Wee C, Meyerson J, Eiferman D, Skoracki R. Vascularized jejunal mesenteric lymph node transfer: a novel surgical treatment for extremity lymphedema. J Am Coll Surg 2017;225:650-7. DOI PubMed

32. Gustafsson J, Chu SY, Chan WH, Cheng MH. Correlation between quantity of transferred lymph nodes and outcome in vascularized submental lymph node flap transfer for lower limb lymphedema. Plast Reconstr Surg 2018;142:1056-63. DOI PubMed

33. Nguyen AT, Suami H, Hanasono MM, Womack VA, Wong FC, Chang EI. Long-term outcomes of the minimally invasive free vascularized omental lymphatic flap for the treatment of lymphedema. J Surg Oncol 2017;115:84-9. DOI PubMed

34. Maldonado AA, Chen R, Chang DW. The use of supraclavicular free flap with vascularized lymph node transfer for treatment of lymphedema: a prospective study of 100 consecutive cases. J Surg Oncol 2017;115:68-71. DOI PubMed

35. Ciudad P, Agko M, Perez Coca JJ, et al. Comparison of long-term clinical outcomes among different vascularized lymph node transfers: 6-year experience of a single center's approach to the treatment of lymphedema. J Surg Oncol 2017;116:671-82. DOI PubMed

36. Massey MF, Gupta DK. The incidence of donor-site morbidity after transverse cervical artery vascularized lymph node transfers: the need for a lymphatic surgery national registry. Plast Reconstr Surg 2015;135:939e-40e. DOI PubMed

37. Lee M, McClure E, Reinertsen E, Granzow JW. Lymphedema of the upper extremity following supraclavicular lymph node harvest. Plast Reconstr Surg 2015;135:1079e-82e. DOI PubMed PMC

38. Chu CK, Schaverien MV, Chang EI, Hanson SE, Hanasono MM, Selber JC. Intra-abdominal lymph nodes: a privileged donor site for vascularized lymph node transfer. Plast Reconstr Surg Glob Open 2020;8:e2673. DOI PubMed PMC

39. Manrique OJ, Bustos SS, Kuruoglu D, et al. Gastroepiploic lymph node flap harvest for patients with lymphedema: minimally invasive versus open approach. Ann Plast Surg 2020;85:S87-91. DOI PubMed

40. Nguyen AT, Suami H. Laparoscopic free omental lymphatic flap for the treatment of lymphedema. Plast Reconstr Surg 2015;136:1148. DOI PubMed

41. Nguyen AT, Chang EI, Suami H, Chang DW. An algorithmic approach to simultaneous vascularized lymph node transfer with microvascular breast reconstruction. Ann Surg Oncol 2015;22:2919-24. DOI PubMed

42. Schaverien MV, Chang EI. Combined deep inferior epigastric artery perforator flap with vascularized groin lymph node transplant for treatment of breast cancer-related lymphedema. Gland Surg 2021;10:460-8. DOI PubMed PMC

43. Pons G, Abdelfattah U, Sarria J, Duch J, Masia J. Reverse lymph node mapping using indocyanine green lymphography: a step forward in minimizing donor-site morbidity in vascularized lymph node transfer. Plast Reconstr Surg 2021;147:207e-12e. DOI PubMed

44. Hamdi M, Ramaut L, De Baerdemaeker R, Zeltzer A. Decreasing donor site morbidity after groin vascularized lymph node transfer with lessons learned from a 12-year experience and review of the literature. J Plast Reconstr Aesthet Surg 2021;74:540-8. DOI PubMed

45. Chang EI, Ibrahim A, Liu J, et al. Optimizing quality of life for patients with breast cancer-related lymphedema: a prospective study combining DIEP flap breast reconstruction and lymphedema surgery. Plast Reconstr Surg 2020;145:676e-85e. DOI PubMed

46. Chang EI, Schaverien MV, Hanson SE, Chu CK, Hanasono MM. Evolution in surgical management of breast cancer-related lymphedema: the MD Anderson cancer center experience. Plast Reconstr Surg Glob Open 2020;8:e2674. DOI PubMed PMC

47. Masia J, Pons G, Nardulli ML. Combined surgical treatment in breast cancer-related lymphedema. J Reconstr Microsurg 2016;32:1627. DOI PubMed

48. Hanson SE, Chang EI, Schaverien MV, Chu C, Selber JC, Hanasono MM. Controversies in surgical management of lymphedema. Plast Reconstr Surg Glob Open 2020;8:e2671. DOI PubMed PMC

49. Beederman M, Garza RM, Agarwal S, Chang DW. Outcomes for physiologic microsurgical treatment of secondary lymphedema involving the extremity. Ann Surg 2020. DOI PubMed

50. Di Taranto G, Bolletta A, Chen SH, et al. A prospective study on combined lymphedema surgery: Gastroepiploic vascularized lymph nodes transfer and lymphaticovenous anastomosis followed by suction lipectomy. Microsurgery 2021;41:34-43. DOI PubMed

51. Yamamoto T, Yamamoto N, Kageyama T, Sakai H, Fuse Y, Tsukuura R. Lymph-interpositional-flap transfer (LIFT) based on lymphaxiality concept: simultaneous soft tissue and lymphatic reconstruction without lymph node transfer or lymphatic anastomosis. J Plast Reconstr Aesthet Surg 2021:S1748-6815(21)00104. DOI PubMed

52. Yamamoto T, Iida T, Yoshimatsu H, Fuse Y, Hayashi A, Yamamoto N. Lymph flow restoration after tissue replantation and transfer: importance of lymph axiality and possibility of lymph flow reconstruction without lymph node transfer or lymphatic anastomosis. Plast Reconstr Surg 2018;142:796-804. DOI PubMed

53. Chang DW. Lymphaticovenular bypass for lymphedema management in breast cancer patients: a prospective study. Plast Reconstr 
Surg 2010;126:752-8. DOI PubMed

54. Chen R, Mu L, Zhang H, et al. Simultaneous breast reconstruction and treatment of breast cancer-related upper arm lymphedema with lymphatic lower abdominal flap. Ann Plast Surg 2014;73 Suppl 1:S12-7. DOI PubMed

55. Saaristo AM, Niemi TS, Viitanen TP, Tervala TV, Hartiala P, Suominen EA. Microvascular breast reconstruction and lymph node transfer for postmastectomy lymphedema patients. Ann Surg 2012;255:468-73. DOI PubMed

56. Cheng MH, Tee R, Chen C, Lin CY, Pappalardo M. Simultaneous ipsilateral vascularized lymph node transplantation and contralateral lymphovenous anastomosis in bilateral extremity lymphedema with different severities. Ann Surg Oncol 2020;27:5267-76. DOI PubMed PMC

57. Hassan K, Chang DW. The charles procedure as part of the modern armamentarium against lymphedema. Ann Plast Surg 2020;85:e37-43. DOI PubMed

58. Sapountzis S, Ciudad P, Lim SY, et al. Modified Charles procedure and lymph node flap transfer for advanced lower extremity lymphedema. Microsurgery 2014;34:439-47. DOI PubMed

59. Brorson H. Liposuction in lymphedema treatment. J Reconstr Microsurg 2016;32:56-65. DOI PubMed

60. Boyages J, Kastanias K, Koelmeyer LA, et al. Liposuction for advanced lymphedema: a multidisciplinary approach for complete reduction of arm and leg swelling. Ann Surg Oncol 2015;22 Suppl 3:S1263-70. DOI PubMed PMC

61. Greene AK, Voss SD, Maclellan RA. Liposuction for swelling in patients with lymphedema. N Engl J Med 2017;377:1788-9. DOI PubMed

62. Chang EI, Bonillas RG, El-ftesi S, et al. Tissue engineering using autologous microcirculatory beds as vascularized bioscaffolds. FASEB J 2009;23:906-15. DOI PubMed PMC

63. Lähteenvuo M, Honkonen K, Tervala T, et al. Growth factor therapy and autologous lymph node transfer in lymphedema. Circulation 2011;123:613-20. DOI PubMed

64. Hartiala P, Suominen S, Suominen E, et al. Phase 1 Lymfactin ${ }^{\circledR}$ Study: short-term safety of combined adenoviral VEGF-C and lymph node transfer treatment for upper extremity lymphedema. J Plast Reconstr Aesthet Surg 2020;73:1612-21. DOI

65. Honkonen KM, Visuri MT, Tervala TV, et al. Lymph node transfer and perinodal lymphatic growth factor treatment for lymphedema. Ann Surg 2013;257:961-7. DOI PubMed

66. Tammela T, Alitalo K. Lymphangiogenesis: molecular mechanisms and future promise. Cell 2010;140:460-76. DOI PubMed

67. Rochlin DH, Inchauste S, Zelones J, Nguyen DH. The role of adjunct nanofibrillar collagen scaffold implantation in the surgical management of secondary lymphedema: Review of the literature and summary of initial pilot studies. J Surg Oncol 2020;121:121-8. DOI PubMed

68. Classen DA, Irvine L. Free muscle flap transfer as a lymphatic bridge for upper extremity lymphedema. $J$ Reconstr Microsurg 2005;21:93-9. DOI PubMed

69. Rockson SG. Lymphedema after breast cancer treatment. N Engl J Med 2018;379:1937-44. DOI PubMed

70. Rockson SG, Tian W, Jiang X, et al. Pilot studies demonstrate the potential benefits of antiinflammatory therapy in human lymphedema. JCI Insight 2018;3:123775. DOI PubMed PMC

71. Johnson AR, Asban A, Granoff MD, et al. Is immediate lymphatic reconstruction cost-effective? Ann Surg 2019. DOI PubMed

72. Boccardo F, Valenzano M, Costantini S, et al. LYMPHA technique to prevent secondary lower limb lymphedema. Ann Surg Oncol 2016;23:3558-63. DOI PubMed

73. Beelen LM, van Dishoeck AM, Tsangaris E, et al. Patient-reported outcome measures in lymphedema: a systematic review and COSMIN analysis. Ann Surg Oncol 2021;28:1656-68. DOI PubMed

74. Fish ML, Grover R, Schwarz GS. Quality-of-Life outcomes in surgical vs nonsurgical treatment of breast cancer-related lymphedema: a systematic review. JAMA Surg 2020;155:513-9. DOI PubMed 